\title{
A Theoretical Survey of the Spreading Modulation of the New GPS Signals (L1C, L2C, and L5)
}

\author{
Ilir F. Progri' ${ }^{1}$, Matthew C. Bromberg ${ }^{2}$, William R. Michalson ${ }^{3}$, Jinling Wang ${ }^{4}$ \\ ${ }^{1}$ Giftet Inc., 5 Euclid Ave. \#3, Worcester, MA 01610, USA \\ ORCID: 0000-0001-5197-1278 \\ ${ }^{2}$ Elected Engineering, $M A$ \\ ${ }^{3}$ Worcester Polytechnic Institute, Worcester, MA \\ ${ }^{4}$ University of New South Wales, Sydney, Australia
}

Correspondence should be addressed to Ilir Progri; iprogri@giftet.com

Received March 23, 2017; Revised March 24, 31, 2017-June 7, 2017, Accepted July 16, 2017; Published November 1, 2017.

Scientific Editor-in-Chief/Editor: Ilir F. Progri

Copyright (C) 2017 Ilir F. Progri et al. This is an open access article distributed under the Creative Commons Attribution License, which permits unrestricted use, distribution, and reproduction in any medium, provided the original work is properly cited.

In this paper a survey of the spreading modulation of the new GPS signals (L1C, L2C, and L5) is considered. The new signals seem to offer several improvements which range from higher power, better code selection, and improved modulation schemes which offer receiver designers the opportunity to obtain unmatched performance in many ways such as in the case of a maximum likelihood GPS receiver.

For example the Multiplexed Binary Offset Carrier (MBOC) spreading modulation has been recommended by the GPS-GALILEO Working Group on interoperability and compatibility because the MBOC $(6,1,1 / 11)$ power spectral density is a mixture of $\operatorname{BOC}(1,1)$ spectrum and $\operatorname{BOC}(6,1)$ spectrum, that would be used by GALILEO for its Open Service (OS) signal at L1 frequency, and also by GPS for its modernized L1 Civil (L1C) signal. It is suggested that a number of different time waveforms can produce the $\operatorname{MBOC}(6,1,1 / 11)$ spectrum, allowing flexibility in implementation and maintaining interoperable waveforms for GALILEO and GPS. On the other hand, the timemultiplexed BOC (TMBOC) implementation interlaces $\mathrm{BOC}(6,1)$ and $\mathrm{BOC}(1,1)$ spreading symbols in a regular pattern, whereas composite BOC (CBOC) uses multilevel spreading symbols formed from the weighted sum of $\operatorname{BOC}(1,1)$ and $\operatorname{BOC}(6,1)$ spreading symbols, interplexed to form a constant modulus composite signal.

New L1C provides a number of advanced features, which includes $75 \%$ of the power in a pilot component for enhanced signal tracking, advanced Weil-based spreading codes, an overlay code on the pilot that provides data message synchronization, support for improved reading of clock and ephemeris by combining message symbols across messages, advanced forward error control coding, and data symbol interleaving to combat fading. The resulting design offers receiver designers the opportunity to obtain a greatly improved performance in many ways.

In this paper we perform a theoretical survey of the new signals and suggest a new code spreading modulation scheme which could provide even further improvements to the new GPS III signals. 
Index Terms - Spreading modulation, new GPS signals, GPS III signals, L1C, L2C, L5, BOC, MBOC, CBOC, time-domain analysis, modulation schemes.

\section{Introduction}

The Global Positioning System (GPS) as we already know has begun a revolution for providing accurate position, velocity (or navigation), and timing information since the early 1970. As we know GPS consists of three segments: the space segment, the control segment, and the user segment. The original GPS space segment consisted of $24+3$ GPS satellites. Originally, GPS satellites' role was to continuously broadcast GPS ranging signals on the two frequencies L1 and L2 with signal specifications in GPS-ICD-200. However, as we know the original GPS was unable to provide users with required capabilities of today's needs in position, velocity (or navigation), and timing accuracy worldwide and especially indoors, underground, and underwater.

In order for GPS to meet these added requirements it was suggested that GPS undergo two major phases. Phase I as we know is called the GPS modernization and Phase II as we know is called the GPS III.

First, in order to benefit users worldwide GPS is undergoing continual modernization since mid-1990s. With the Selective Availability (SA) turned off (or set to zero) in May 2000, a new era of GPS modernization was initiated which continued with other subsequent improvements in accuracy through various enhancements to capabilities and operation of the space and control segments although the original set of GPS signals was used. In 2005 the transmission of the L2 civil (L2C) begun with the launch of the IIR-14(M) satellite along with the modernized military signal known as the M-code signal. The L5 signal known as the third civil signal will be transmitted from Block IIF satellites [1]-[6]. Other improvements in accuracy results from enhancements in monitoring and satellite technologies such as clocks and operations while the United States plans to continue providing these capabilities free of user fees and free, open signal description and other technical information needed for development of GPS receivers using GPS civil signals.

Second, the Phase II as we know it is called the GPS III or the next generation of satellites and a modernized Control Segment, called OCX, continues, which will lead to greatly enhanced capabilities beginning early in the next decade. In addition to current signals, the new civil signal called L1C which will be broadcast on the L1 carrier frequency is an integral part of the GPS III capabilities being developed. The new signal is designed to be interoperable with Galileo's Open Service signal and virtually seamless interoperability with signals from Japan's Quazi-Zenith Satellite System (QZSS).

There are several unique opportunities taken into consideration while designing the L1C signal such as L1 center frequency, advancements in signal design ${ }^{i}$ knowledge and in statistical receiver signal processing, developments in circuit technologies and supporting communications services [1], [6].

While the L1C signal design includes several topics such as signal structure ${ }^{\mathrm{ii}}$, signal's spreading codes and overlay codes, spreading modulation, message structure and encoding and decoding of message information. The new GPS ICD-800 provides the complete description of these aspects of the new L1C signal.

However, we believe that added capabilities in the spreading modulation maybe achieved without added complication as currently depicted in the new L1C signal design.

The purpose of this paper is to revisit the spreading modulation of the GPS signal and propose a new modulation scheme called the variable binary offset modulation (VBOC) as a possible candidate for the new L1C signal modulation.

The paper is organized as follows. First we describe the traditional binary phase shift keying modulation or (BPSK) such as signal autocorrelation function (ACF) and power spectral density (PSD). Second we do the same for the binary offset code modulation $\operatorname{BOC}(1,1)$ and third we do the same for the $\operatorname{VBOC}(2,1, \alpha)$ in comparison to $\operatorname{BOC}(2,1)$. Fourth we provide a discussion on the added capability of the $\operatorname{VBOC}(2,1, \alpha)$ spreading modulation over the proposed $\operatorname{MBOC}(6,1,1 / 11)$ spreading modulation. Fifth, we provide the numerical, theoretical results. Sixth, we provide the conclusion.

\section{BPSK Signal}

The BPSK signal (as shown in Fig. 1 (a)) also known as the phase shift keying with rectangular spreading symbols (PSK-R) is the traditional spreading sequence modulation used by the $\mathrm{C} / \mathrm{A}$ code in the $\mathrm{L} 1$ frequency.

As we know it the chipping rate for the C/A code is 1.023 Mcps and therefore the chipping period is $T_{0}=1 / 1.023 \mu \mathrm{s}$. 
For acquisition and tracking purposes the ACF of the BPSK signal is used.

The ACF of the BPSK signal, $r_{B P S K}(\tau)$, for $T_{0}=$ $1 / 1.023 \mu \mathrm{s}$ (as shown in Fig. 1 (b)) is given by:

$$
r_{B P S K}(\tau)=\mid \begin{array}{cc}
1-\frac{|\tau|}{T_{0}}, & |\tau| \leq T_{0} \\
0, & \text { otherwise }
\end{array}
$$

The slope of the ACF is very important as it is directly linked with acquisition time and with the bandwidth of the tracking loop.

The PSD of the ACF can be used to make accurate calculation of the effective bandwidth of the signal. Without showing all the steps the PSD, $R_{B P S K}(f)$, (see Fig. 1(c)) of the ACF of the BPSK signal, $r_{B P S K}(\tau)$, is its Fourier Transform and it is given by

$$
R_{B P S K}(f)=\mathcal{F}\left\{r_{B P S K}(\tau)\right\}=T_{0} \operatorname{sinc}^{2}\left(\frac{f}{T_{0}}\right)
$$

However, as seen by the PSD of the sequence, the effective bandwidth of the signal is about $2 \mathrm{MHz}$.

Let assume that the signal is ideally bandlimited to the complex bandwidth $\beta_{r}$ which is typically $2 \mathrm{MHz}$ for $\mathrm{C} / \mathrm{A}$ code receivers.

The smallest RMS code-tracking error (CTE) (or the information theoretic lower bound) that can be achieved in white noise using any discriminator is [7]

$$
\sigma_{L B}=\frac{1}{2 \pi \bar{\beta}_{r m s}} \sqrt{\frac{B_{L}}{\lambda \frac{C}{N_{0}}}}
$$

Where

$B_{L}$ is the one-sided equivalent rectangular bandwidth of the code-tracking loop;

$C / N_{0}$ is the carrier-power-to-noise-density ratio;

$\bar{\beta}_{r m s}$ is the root mean square bandwidth of a band-limited signal having units of power defined by [7]

$$
\bar{\beta}_{r m s}=\int_{-\beta_{r}}^{\beta_{r}} f^{2} \overline{G_{s}}(f) d f
$$

$\lambda$ is the power fraction after bandlimiting to $\beta_{r}$ which is given by [7]

目 $\lambda=\int_{-\beta_{r} / 2}^{\beta_{r} / 2} G_{s}(f) d f$

So that the normalized PSD function is [7]

$$
\overline{G_{s}}(f)=G_{s}(f) / \lambda
$$

Assuming that the loop bandwidth is $B_{L}=1 \mathrm{~Hz}$, $C / N_{0}=30 \mathrm{~dB}$, and no multipath using (2) through (6) we obtain the following calculations for the smallest RMS CTE that can be achieved in white noise for the C/A code (or PSKR or BPSK) signal

$$
\sigma_{L B}=\left|\begin{array}{c}
12.25 \\
5.48 \mathrm{~cm} \\
3.54
\end{array} \quad \beta_{r}=\right| \begin{aligned}
& 2 \\
& 10 \mathrm{MHz} \\
& 20
\end{aligned}
$$

However, as predicted both from calculations and from the experimental data the CTE increases rapidly in the presence of multipath [7].

An increase of the effective bandwidth by a factor of 5 (or 10) gives only a decrease of the RMS CTE by a factor of 2.23 (or 3.46).

\section{$3 \quad \operatorname{BOC}(1,1)$}

BOC modulation was designed specifically to outperform the PSK-R modulation while using the same or even less bandwidth while at the same time using simpler transmitter and receiver designs.

While essential characteristics of the BOC modulations are currently well understood and explained such as the modulations, the approach for generating them, and the expressions of the second-order statistics we will consider only the expression of the $\mathrm{BOC}(1,1) \mathrm{ACF}$ and then its PSD to enable similar calculations of the RMS CTE.

The ACF of the BOC $(1,1)$ signal (see Fig. 2 (a)) is given by

$$
r_{B P S K}(\tau)=\mid \begin{array}{cc}
1-\frac{|\tau|}{T_{0}}, & |\tau| \leq \frac{T_{0}}{2} \\
-1+\frac{|\tau|}{T_{0}} & \frac{T_{0}}{2} \leq|\tau| \leq T_{0} \\
0, & \text { otherwise }
\end{array}
$$

As seen in Fig. 2 (b) the ACF of the $\operatorname{BOC}(1,1)$ is much sharper than the ACF of the PSK-R signal.

Without showing all the steps the PSD, $R_{B O C}(f)$, (see Fig. 2 (c)) of the ACF of the $\operatorname{BOC}(1,1)$ signal, $r_{B O C(1,1)}(\tau)$, is its Fourier Transform and it is given by

$$
R_{B O C(1,1)}(f)=\mathcal{F}\left\{r_{B O C(1,1)}(\tau)\right\}=T_{0} \operatorname{sinc}^{2}\left(\frac{f}{T_{0}}\right) \sin ^{2}\left(\frac{\pi f}{2 T_{0}}\right)
$$

Assuming that the loop bandwidth is $B_{L}=1 \mathrm{~Hz}$, $C / N_{0}=30 \mathrm{~dB} \mathrm{~dB}$, and no multipath using equations (2) through (6) we obtain the following calculations for the smallest RMS CTE that can be achieved in white noise for the BOC $(1,1)$ code signal 


$$
\sigma_{L B}=\left|\begin{array}{l}
7.07 \\
3.16 \mathrm{~cm} \\
2.04
\end{array} \quad \beta_{r}=\right| \begin{aligned}
& 2 \\
& 10 \mathrm{MHz} \\
& 20
\end{aligned}
$$

An increase of the effective bandwidth by a factor of 5 (or 10) gives only a decrease of the RMS CTE by a factor of 2.23 (or 3.47); however, the initial and the final values are different.

At $2 \mathrm{MHz}$ the RMS code tracking error for the $\mathrm{BOC}(1,1)$ is only $57.7 \%$ of the RMS code tracking error for the PSK-R signal. And the same result is true also for the RMS code tracking error for the $\mathrm{BOC}(1,1)$ at $20 \mathrm{MHz}$, which means that BOC $(1,1)$ modulation enables more efficient spectrum utilization than the PSK-R modulation.

\section{$4 \operatorname{VBOC}(2,1, \alpha)$}

An increase of the sub-carrier frequency by a factor of 2 or $\operatorname{BOC}(2,1)$ would logically result in an increase of the bandwidth utilization and in a decrease of the RMS code tracking error.

The close form expression of the ACF of the $\operatorname{VBOC}(2,1,20)$ signal is not provided. Similarly the closed form expression of the PSD of $\operatorname{VBOC}(2,1, ? \alpha)$ is provided in [10], [11]. More complete analysis including the closed form expression of multipath analyses will be provided in a separate journal paper.

Assuming that the loop bandwidth is $B_{L}=1 \mathrm{~Hz}$, $C / N_{0}=30 \mathrm{~dB}$, and no multipath using equations (2) through (6) we obtain the following calculations for the smallest RMS CTE that can be achieved in white noise for the $\operatorname{VBOC}(2,1, \alpha)$ code signal is provided in Table 1.

\section{Numerical, Theoretical Results}

Preliminary numerical, theoretical results section contains the first set of simulation results of pulse function, ACF, PSD for: (1) BPSK (or PSK-R); (2) BOC $(1,1),(3) \operatorname{VOC}(2,1, \alpha)$, and (4) BPSK (or PSK-R); $\operatorname{BOC}(1,1)$, and $\operatorname{VOC}(2,1, \alpha)$ signals.

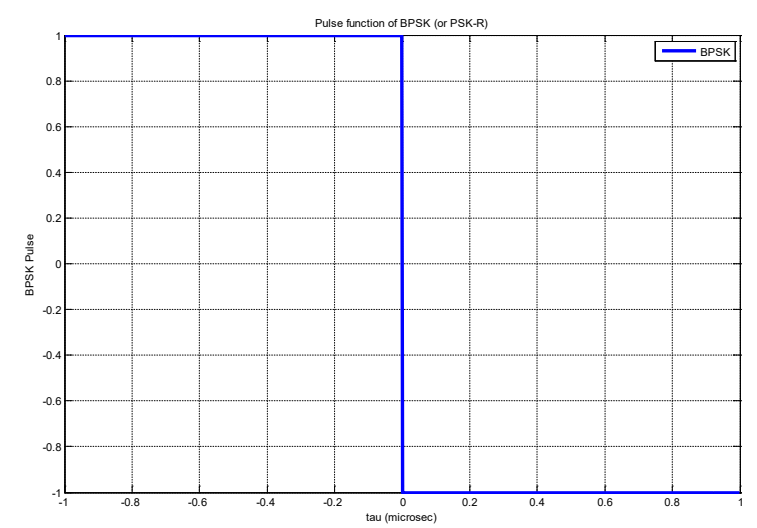

(a) Pulse function of BPSK (or PSK-R) signal in TD.

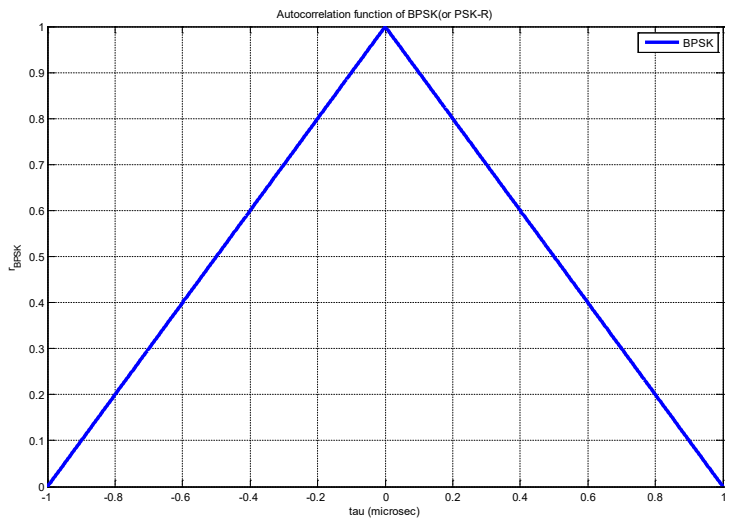

(b) ACF of BPSK (or PSK-R) signal in TD.

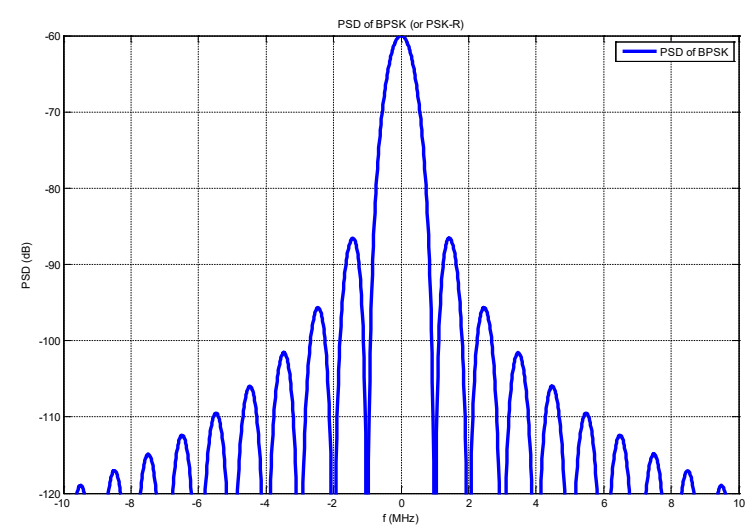

(c) PSD of BPSK (or PSK-R) signal in FD.

FIGURE 1: BPSK (or PSK-R) signal: (a) Pulse function in the TD; (b) ACF of BPSK (or PSK-R) in TD; (c) PSD of BPSK (or PSK-R) in FD. 


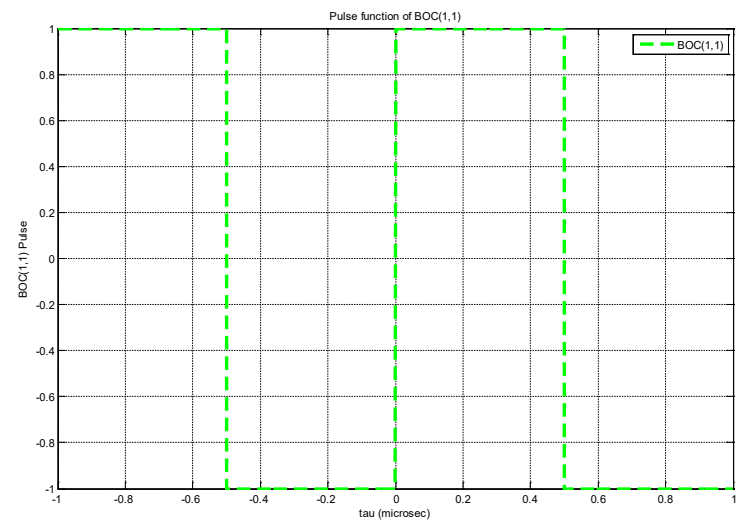

(a) Pulse function of BPSK (or PSK-R) signal in TD.

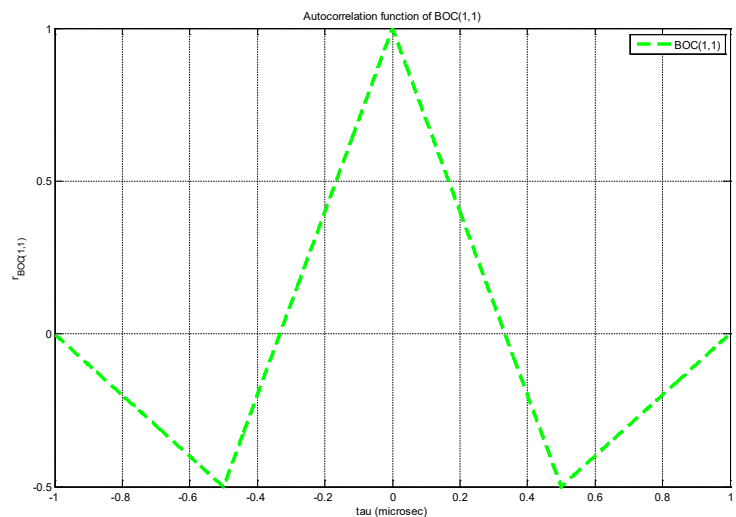

(b) ACF of BPSK (or PSK-R) signal in TD.

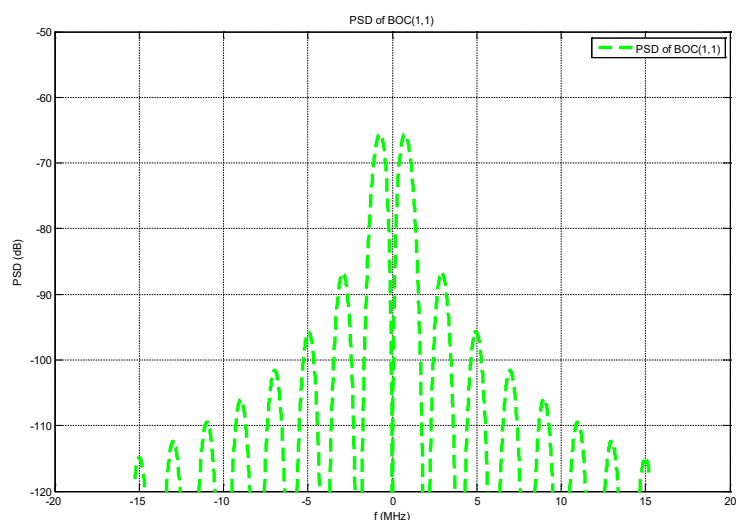

(c) PSD of BOC(1,1) signal in FD.

FIGURE 2: BOC(1,1) signal: (a) Pulse function in the TD; (b) $\mathrm{ACF}$ of $\mathrm{BOC}(1,1)$ in TD; (c) PSD of $\mathrm{BOC}(1,1)$ in FD.

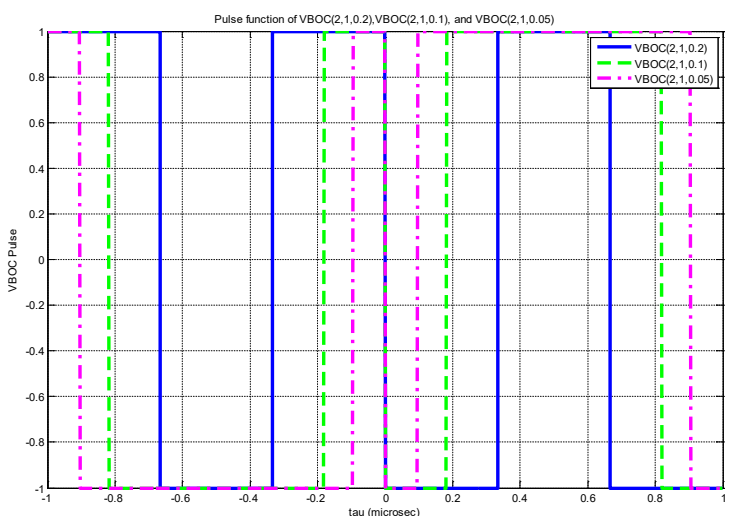

(a) $\operatorname{VBOC}(2,1, \alpha)$ signal for $\alpha=0.2$ solid and blue, $\alpha=0.1$ green and dash, and $\alpha=0.05$ magenta and dot dash, in TD.

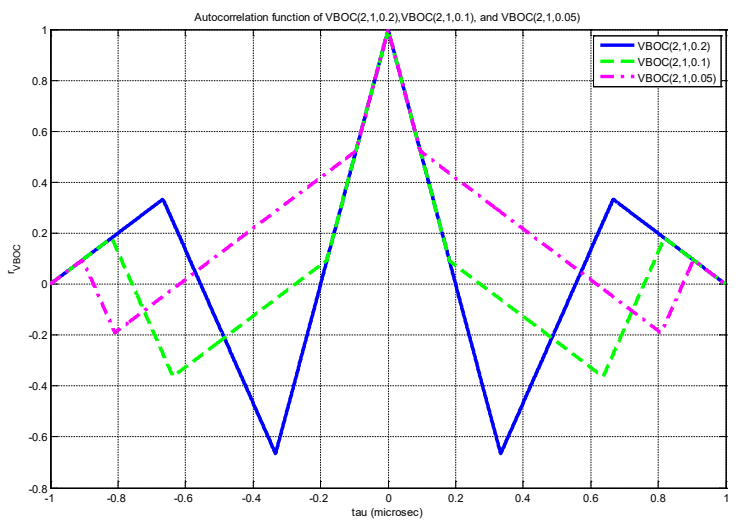

(b) $\operatorname{VBOC}(2,1, \alpha)$ for $\alpha=0.2$ solid and blue, $\alpha=0.1$ green and dash, and $\alpha=0.05$ magenta and dot dash, in TD.

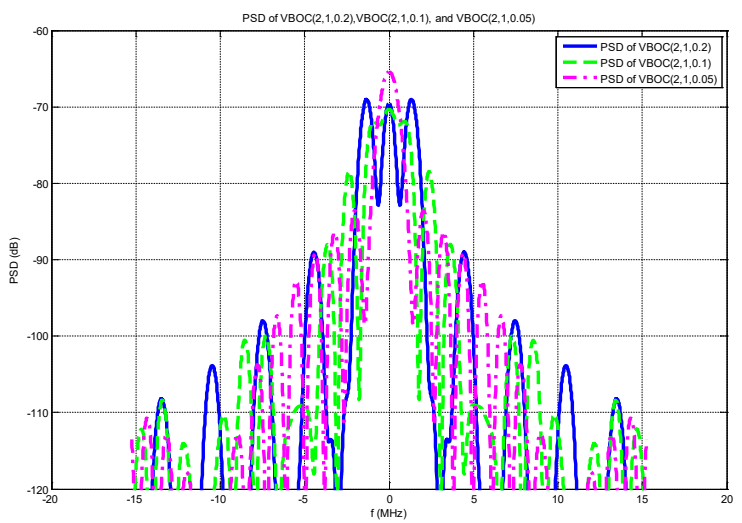

(c) PSD of $\operatorname{VBOC}(2,1, \alpha)$ for $\alpha=0.2$ solid and blue, $\alpha=0.1$ green and dash, and $\alpha=0.05$, magenta and dot dash, in FD.

Figure 3: $\operatorname{VBOC}(2,1, \alpha)$ signal: (a) Pulse function in the TD; (b) ACF of BOC $(1,1)$ in TD; (c) PSD of BOC $(1,1)$ in FD. 


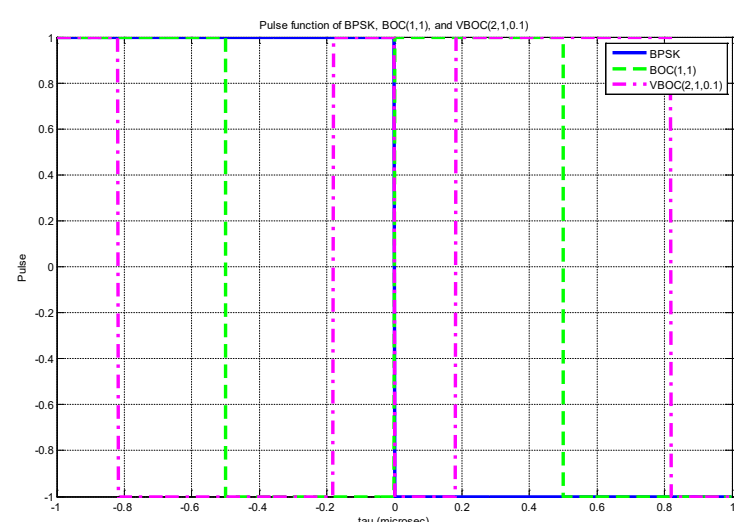

(a) PSK-R, solid and blue, BOC(1,1), green and dash, and $\operatorname{VBOC}(2,1,0.1)$, magenta dot dash, signals in TD.

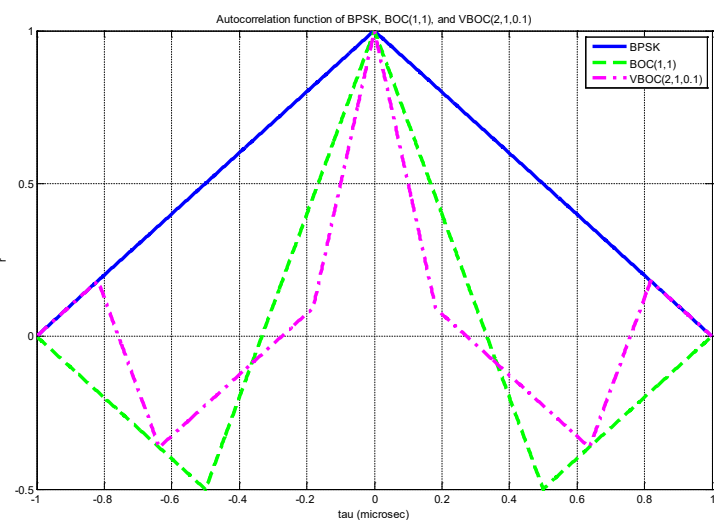

(b) PSK-R solid and blue, $\mathrm{BOC}(1,1)$ green and dash and $\operatorname{VBOC}(2,1,0.1)$ magenta dot dash signals in TD.

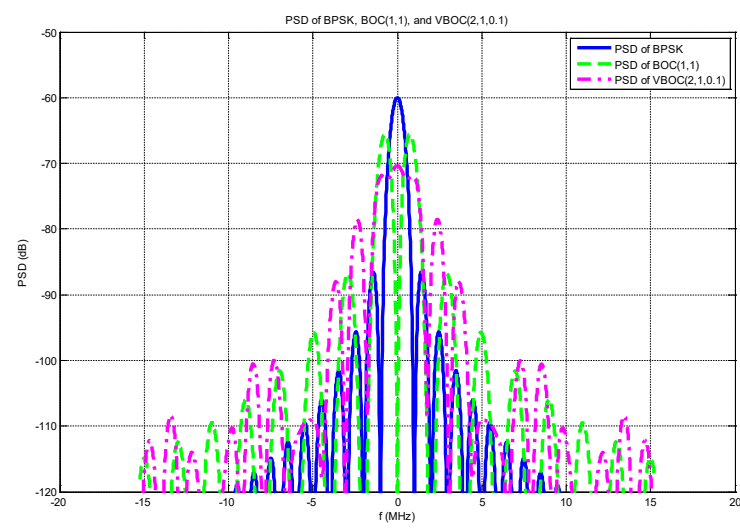

(c) PSD of PSK-R solid and blue, BOC $(1,1)$ green and dash and $\operatorname{VBOC}(2,1,0.1)$ magenta dot dash in FD.

FIGURE 4: PSK-R, BOC(1,1), VBOC(2,1,0.1) signals: (a) Pulse function of PSK-R, $\operatorname{BOC}(1,1), \operatorname{VBOC}(2,1,0.1)$ in the TD; (b) ACF of PSK-R, BOC(1,1), VBOC $(2,1,0.1)$ in TD; (c) PSD of PSK-R, BOC $(1,1), \operatorname{VBOC}(2,1,0.1)$ in FD.
TABLE 1: Computation analysis of the RMS code tracking error, $\sigma_{L B}$, for $\operatorname{VBOC}(2,1, \alpha)$ signal.

\begin{tabular}{c|c|c|c}
\hline \hline$\alpha / \beta_{r}$ & $2 \mathrm{MHz}$ & $10 \mathrm{MHz}$ & $20 \mathrm{MHz}$ \\
\hline \hline 0.2 & $6.12 \mathrm{~cm}$ & $2.74 \mathrm{~cm}$ & $1.94 \mathrm{~cm}$ \\
0.1 & $8.33 \mathrm{~cm}$ & $2.66 \mathrm{~cm}$ & $1.89 \mathrm{~cm}$ \\
0.05 & $9.82 \mathrm{~cm}$ & $2.73 \mathrm{~cm}$ & $1.91 \mathrm{~cm}$ \\
\hline
\end{tabular}

\section{$5.1 \quad$ BPSK (or PSK-R) signal}

In this subsection we present, numerical results of the BPSK (or PSK-R) signal using the exact closed form expression found in this paper and in Progri 2015 [8], [9].

Figure 1 (a) indicates the pulse shape of BPSK (or PSK-R) signal in TD.

Figure 1 (b) depicts the ACF of the BPSK (or PSK-R) signal in TD.

Figure 1 (c) depicts the PSD of the ACF of the PSK-R in FD.

\section{$5.2 \quad$ BOC(1,1) signal}

In this subsection we present, numerical results of the $\operatorname{BOC}(1,1)$ signal using the exact closed form expression found in this paper and in Progri 2015 [8], [9].

Figure 2 (a) indicates the pulse shape of $\operatorname{BOC}(1,1)$ signal.

Figure 2 (b) depicts the ACF of the BOC $(1,1)$ in TD.

Figure 2 (c) depicts the PSD of the ACF of the BOC $(1,1)$ in FD.

BOC $(1,1)$ shows superior performance against BPSK.

\section{$5.3 \quad \operatorname{VBOC}(2,1, \alpha)$ signal}

In this subsection we present, numerical results of the $\operatorname{VBOC}(2,1, \alpha)$ signal using the exact closed form expression found in this paper and in Progri 2015 [10], [11].

Figure 3 (a) indicates the pulse shape of $\operatorname{VBOC}(2,1, \alpha)$ for $\alpha=\{0.2,0.1,0.05\}$ signals in TD.

Figure 3 (b) depicts the ACF of the $\operatorname{VBOC}(2,1, \alpha)$ for $\alpha=$ $\{0.2,0.1,0.05\}$ in TD.

Figure 3 (c) depicts the PSD of the ACF of $\operatorname{VBOC}(2,1, \alpha)$ for $\alpha=\{0.2,0.1,0.05\}$ in FD.

\subsection{PSK-R (or BPSK) vs. BOC $(1,1)$ vs. VBOC $(2,1, \alpha)$ signals}

In this subsection we present, numerical results of the PSK$\mathrm{R}$ (or BPSK) vs. $\operatorname{BOC}(1,1)$ vs. $\operatorname{VBOC}(2,1, \alpha)$ signals using the exact closed form expression found in this paper and in Progri 2015 [8]-[11]. 
Figure 4 (a) indicates the pulse shape of PSK-R (or BPSK), $\operatorname{BOC}(1,1)$, and $\operatorname{VBOC}(2,1, \alpha)$ signals in TD.

Figure 4 (b) depicts the ACF of the PSK-R, BOC $(1,1)$, and $\operatorname{VBOC}(2,1,0.1)$ in TD.

Figure 4 (c) depicts the PSD of the ACF of the PSK-R, $\operatorname{BOC}(1,1)$, and $\operatorname{VBOC}(2,1,0.1)$ in FD.

Based on the information shown in Fig.4 variable signal modulation shows superior performance against either BPSK or $\operatorname{BOC}(1,1)$.

\section{Conclusions}

In summary we have revisited the spreading modulation techniques so far employed in the GNSS signals namely the PSK-R (or BPSK) and BOC $(1,1)$.

We have proposed a $\operatorname{VBOC}(2,1, \alpha)$ signal which is a version of the BOC signal but with a variable transition of the binary offset signal.

It appears that $\operatorname{VBOC}(2,1,0.1)$ could be a better candidate than the currently suggested $\operatorname{TMBOC}(6,1,4 / 33$ ) (see [3]) because it achieves similar main autocorrelation peak as the smaller out of phase autocorrelation peaks.

In the future, GNSS receivers with wide effective bandwidth will be preferred to enable more sophisticated signal processing on the receiver; therefore, $\operatorname{VBOC}(2,1,0.1)$ would be the preferred modulation.

If we assume a $20 \mathrm{MHz}$ signal bandwidth for processing then the smallest RMS code tracking error is $1.89 \mathrm{~cm}$.

It remains to perform these studies in the presence of multipath. We suspect that similar computation performance will be obtained in the presence of multipath.

A time multiplexed version of VBOC could be our desired spreading modulation scheme. However, this remains to be investigated [14].

Since 2007 when this paper was originally presented a lot has occurred [8]-[15]. Although, this paper lacked a lot of mathematical background found in [8]-[15], it served as the bridge between the research that was initially published prior to 2007 [16]-[26] and the research that was published after 2007 [8]-[15].

\section{Acknowledgement}

This work was supported by Giftet Inc. executive office.

\section{References}

[1] I. Progri, M.C. Bromberg, W.R. Michalson, J. Wang, "A theoretical survey of the spreading modulation of the new GPS signals (L1C, L2C, and L5)," in Proc. ION-NTM 2007, San Diego, CA, pp. 561-569, Jan. 2007.

[2] J.W. Betz, M.A. Blanco, C.R. Cahn, P.A. Dafesh, C.J. Hegarty, K.W. Hudnut, V. Kasemsri, R. Keegan, K. Kovach, Capt L.S. Lenahan, H.H. Ma, J.J. Rushanan, D. Sklar, T.A. Stansell, C.C. Wang, S.K. Yi, "Description of the L1C Signal," in Proc. ION-GNSS 2006, Fort Worth, TX, Sep. 2006.

[3] J.W. Betz, M.A. Blanco, C.R. Cahn, P.A. Dafesh, C.J. Hegarty, K.W. Hudnut, V. Kasemsri, R. Keegan, K. Kovach, Capt L.S. Lenahan, H.H. Ma, J.J. Rushanan, D. Sklar, T.A. Stansell, C.C. Wang, S.K. Yi, "Description of the L1C Signal," Presentation in Proc. ION-GNSS 2006, Fort Worth, TX, Sep. 2006 (personal information).

[4] G.W. Hein, J.A. A-Rodriguez, S. Wallner, A. R. Pratt, J. Owen, J.-L. Issler, J.W. Betz, C. J. Hegarty, Lt Sean Lenahan, J.J. Rushanan, A. L. Kraay, T.A. Stansell, "MBOC: the new optimized spreading modulation recommended for GALILEO L1 OS and GPS L1C," in Proc. IEEE/ION-PLANS 2006, Coronado, CA, pp. 883892, 25-27 Apr. 2006, DOI: https://doi.org/10.1109/PLANS.2006.1650688.

[5] J.W. Betz, C.R. Cahn, P.A. Dafesh, C.J. Hegarty, K.W. Hudnut, Capt A.J. Jones, R. Keegan, K. Kovach, Capt L.S. Lenahan, H.H. Ma, J.J. Rushanan, T.A. Stansell, C.C. Wang, S.K. Yi, "L1C signal design options," in Proc. IONNTM 2006, pp. 685-697, Jan. 2006.

[6] I.F. Progri, "GPS L5 signal acquisition and tracking under unintentional interference or jamming," in Proc. IONNTM 2006, Monterey, CA, pp. 112-121 Jan. 2006.

[7] J. Betz, "Binary offset carrier modulations for radionavigation," NAVIGATION J. of Inst. Nav., vol. 48, no. 4, pp. 227-246, winter 2001-2002, DOI: https://doi.org/10.1002/j.2161-4296.2001.tb00247.x.

[8] I. Progri, "VBOC1 $(\alpha)$ generalized multidimensional geolocation modulation waveforms," J. Geoloc. GeoInf. Geoint., vol. 2015, pp. 19-31, Nov. 2015, DOI: http://doi.org/10.18610/JG3.2015.082101.

[9] I. Progri, "VBOC1 $(\alpha)$ ACF pure signal optimization," $J$. Geoloc. GeoInf. Geoint., vol. 2015, pp. 32-43, Nov. 2015, DOI: http://doi.org/10.18610/JG3.2015.082102. 
[10] I. Progri, "VBOC2 $(\alpha, 1-\alpha)$ generalized multidimensional geolocation modulation waveforms," J. Geoloc. GeoInf. Geoint., vol. 2015, pp. 44-56, Nov. 2015, DOI: http://doi.org/10.18610/JG3.2015.082103.

[11] I. Progri, "VBOC2 $(\alpha, 1-\alpha)$ ACF pure signal optimization," J. Geoloc. GeoInf. Geoint., vol. 2015, pp. 56-69, Nov. 2015, DOI: http://doi.org/10.18610/JG3.2015.082104.

[12] I. Progri, "VBOC $1(\alpha)$ and $\operatorname{VBOC} 2(\alpha, 1-\alpha)$ generalized multidimensional geolocation modulation waveforms - technical report," J. Geoloc. GeoInf. Geoint., vol. 2015, pp. 70-82, Nov. 2015, DOI: http://doi.org/10.18610/JG3.2015.082105.

[13]I. Progri, Indoor Geolocation Systems-Theory and Applications. Vol. I, $1^{\text {st }}$ ed., Worcester, MA: Giftet Inc., $\sim 800$ pp., 2017 (not yet available in print).

[14]I. Progri, “On generalized multi-dimensional geolocation modulation waveforms," in Proc. IEEE/ION-PLANS 2012, Myrtle Beach, SC, pp. 919-951, Apr. 2012, DOI: https://doi.org/10.1109/PLANS.2012.6236835.

[15]I. Progri, Geolocation of RF Signals-Principles and Simulations. $1^{\text {st }}$ e., New York, NY: Springer SBM, LLC, 330 pp., Jan. 2011, DOI: http://doi.org/10.1007/978-14419-7952-0.

[16] M.C. Bromberg, I. Progri, "An anti-jam GPS receiver, using Markov Chain, Monte Carlo integration," in Proc IEEE/ION PLANS 2006, Coronado, CA, pp. 957-962, Apr. 2006 ,

DOI: https://doi.org/10.1109/PLANS.2006.1650696.

[17] M.C. Bromberg, I. Progri, "Bayesian parameter estimation for time and frequency synchronization," in Proc. WTS 2005, Pomona, CA, pp. 127-130, Apr. 2005, DOI: https://doi.org/10.1109/WTS.2005.1524776.

[18] I. Progri, M.C. Bromberg, W.R. Michalson, "Maximum likelihood GPS parameter estimation," Navigation, vol. 52, no. 4, pp. 229-238, winter 2005-2006, DOI: http://doi.org/10.1002/j.2161-4296.2005.tb00365.x, URL: http://giftet.com/Progri/Progri_2005_winter_Navigation.p df.

\footnotetext{
i Signal structure is the arrangement of and relations between the parts or elements of the signal. Signal design is the plan or drawing produced to show the look and function or workings of the signal structure before it is produced and transmitted from the satellite or transmitter.
}

[19]I. Progri, M.C. Bromberg, J. Wang, "Markov Chain, Monte Carlo global search and integration for Bayesian, GPS, parameter estimation," Navigation, vol. 56, no. 3, pp. 195-204, fall 2009, DOI: http://doi.org/10.1002/j.21614296.2009.tb01755.x.

[20] W.R. Michalson, I. Progri, "Reconfigurable geolocation system," US Patent 7,079,025, July 2006.

[21]I.F. Progri, "An assessment of indoor geolocation systems," Ph.D. Dissertation, Worcester Polytechnic Institute, 408 pp, May 2003, URL: http://giftet.com/Progri/Progri_2003_05_Ph.D._Dissertati on.pdf.

[22]I. Progri, J.M. Hill, W.R. Michalson, "An investigation of the pseudolite's signal structure for indoor applications," in Proc. ION-AM 2001, Albuquerque, NM, pp. 453-462, June 2001.

[23]I. Progri, W.R. Michalson, "The impact of proposed pseudolite's signal structure on the receiver's phase and code error," in Proc. ION-AM 2001, Albuquerque, NM, pp. 414-422, June 2001.

[24]I. Progri and W.R. Michalson, "An alternative approach to multipath and near-far problem for indoor geolocation systems," in Proc. $14^{\text {th }}$ Inter. Tech. Mtg. Sat. Div. ION (ION GPS 2001), Salt Lake City, UT, pp. 1434-1443, Sep. 2001.

[25]I. Progri, W.R. Michalson, J. Wang, M.C. Bromberg, R.J. Duckworth, "Requirements of a C-CDMA pseudolite indoor geolocation system," J. Geol. Geoinfo. Geointel., vol. 2017, article ID 2017071605, 5 pg., Nov. 2017. DOI: http://doi.org/10.18610/JG3.2017.071605, URL: http://www.giftet.com/JG3/2017/071605.pdf.

[26] I. Progri, W.R. Michalson, J. Wang, M.C. Bromberg, "Indoor geolocation using FCDMA pseudolites: signal structure and performance analysis," Navigation, vol. 54, no. 3, pp. 242-256, fall 2007, DOI: http://doi.org/10.1002/j.2161-4296.2007.tb00407.x, URL: http://giftet.com/Progri/Progri_2007_fall_Navigation.pdf.

ii ditto 